\title{
Trends in the management of registered sexual offenders across England and Wales: a geographical approach to the study of sexual offending
}

Kirsty Hudson, Chris Taylor \& Andrew Henley

\begin{abstract}
Social scientists, and geographers in particular, have long been interested in examining spatial patterns of offending in order to generate a "geography" of crime and criminality. This paper examines what value, if any, a geographical approach to the study of sexual offending might offer. Utilising published official data from England and Wales it presents for the first time geographical analyses of the registration, risk assessment and management of Registered Sexual Offenders (RSOs) across 42 Multi-Agency Public Protection Arrangement (MAPPA) areas. In doing so it considers and evaluates the methodological issues pertaining to the use of such data and such a geographical approach. We conclude that geographical interpretations of both the incidence of RSOs and the rates of risk allocations between MAPPA areas provide valuable insights and raise new questions about the way in which RSOs are managed nationally and are thus worthy of further exploration.
\end{abstract}

\section{Keywords}

Sexual offending, MAPPA, public protection, crime geography, crime mapping

\section{Introduction}

Social scientists, and geographers in particular, have long been interested in examining spatial patterns of offending in order to generate a "geography" of crime and criminality. Indeed the geography of crime has become a distinct sub-discipline within the social sciences and even features as a component of the school national curriculum in England and Wales. Early studies of the role of the physical environment on the incidence of crime can be dated back to the seventeenth century. However, the significance of social geography on patterns of crime and criminality was not recognised until much later (Burgess, 1928; Cohen, 1941) leading to a major growth in the number of geographical studies of crime during the 1970s in the UK and the USA. The geography of crime has also had a further resurgence since the 1990s due to the additional analytical power of geographical information systems (GIS) and the growth of administrative data. There are numerous reasons for this growth, but they can be summarised in the following way. By mapping criminal activity by area it is possible to identify and discern possible underlying factors behind criminal behaviour, which has in turn been used to try to predict the incidence of crime and criminal activity, which has then helped in the targeting of resources within the criminal justice system in terms of crime prevention, law enforcement and in reducing recidivism amongst offenders.

Whilst there can be no doubt that geographical studies of crime and criminality have brought enormous value and benefits to many criminal justice systems around the world they have not developed without criticism. Of most concern has been their tendency to concentrate on situational explanations of crime and deviance which have a propensity to draw attention to "property" or "instrumental" crime (i.e. those concerned with material and economic gain). This focus on "blue collar crime" has led some to argue that this field of research resembles a form of "liberal management" (see, for example, Peet, 1975). Indeed, the rise of Internet and financial crime (or "white collar crime") is a notable absence in the field. But it is also the case that geographical studies 
of crime and criminality have been conspicuously less useful or interested in "expressive" crimes, such as murder or sexual violence (Bottoms, 2007). Given the preponderance of such crimes occur within domestic and familial situations this might not be that surprising. Instead, studies of "expressive" crime have largely taken a psychological approach with a much greater emphasis on individual offenders themselves. This has particularly been the case with regard to sexual offending, where cognitive-behavioural explanations, which suggest that sexually abusive behaviour is, or can be, learned, have tended to dominate.

There are at least two main reasons why a geographical study of "expressive" crimes such as sexual offending might be useful. The first would be to consider what factors other than individual psychological factors might be important in determining the incidence of sexual offending. Whilst a number of studies have attempted to challenge the primacy of psychological approaches to understanding sexual offending (Hudson, 2005), these have often been necessarily small scale and qualitative in their orientation and therefore do not consider other wider geographical factors. However, if such wider geographical factors are absent from our understanding of sexual offending then should there be differences in the prevalence of sexual offences by area, or even country? Irrespective of how unreasonable such a claim is there is a clear dearth of empirical evidence that can be drawn on to qualify both the claim and the importance of these individual psychological factors. If systematic geographical variations did exist then this would raise questions as to what other geographical, sociological or cultural explanations may help explain and/or anticipate patterns of sexual offending. A greater understanding of the contextual factors relating to sexual offending, including a rigorous geographic analysis, is therefore needed. Indeed, if we employ Cohen and Felson's $(\underline{1979}$, p. 592) routine activity theory, it is the "spatio-temporal organisation of social activities" that help determine whether offending is a viable option. This at least invites us to question whether the localities of sexual offenders influence their offending behaviour. Even studies that attempt to make international comparisons to evaluate the impact of different laws regarding sexual offences, such as by Vess, Day, Powell, and Graffam (2013), make little or no reference to any underlying differences in the prevalence of sexual crimes and offenders, let alone variations in the incidence of recorded crime and convictions.

This leads to the second reason why a geographical approach might be useful. As Lowman (2005) argues, the role of control systems on crime patterns can often be a neglected component of many studies, including geographical studies of crime. Any system of practices and institutions that are used to control or manage criminal offenders are inherently geographical and hierarchical, ranging from community policing and support at a local level up to national laws. Even if geographical explanations for "expressive" crimes are less important than they are for "instrumental" crimes both are exposed to the same geographically dispersed control systems. In England and Wales ${ }^{\underline{1}}$ the management and treatment of convicted sexual offenders are the responsibility of various organisations, including currently 35 probation trusts, 123 prisons and 42 regional police forces. These organisations are brought together at a regional level through Multi-Agency Public Protection Arrangements (MAPPAs). $\stackrel{2}{-}$ These in turn are coordinated and supported at a national level by the National Offender Management Service (NOMS). The fact that these arrangements for the management and treatment of Registered Sexual Offenders (RSOs) ${ }^{3}$ are organised in this way creates a distinct geography of control systems across England and Wales, and is itself worthy of geographical analysis. For example, a process study of three MAPPA areas in 2007 identified significant differences in the way in which national guidance was being followed and implemented. 
This in turn raised questions as to the effectiveness of each MAPPA area to minimise the risk of reoffending (Wood, Kemshall, Maguire, Hudson, \& Mackenzie,2007). Despite this a recent analysis of reconviction rates among offenders eligible for MAPPA by the UK Government's Ministry of Justice did not compare reconviction rates of different MAPPA areas (Peck, 2011). Given that the treatment and management of RSOs are often geographically dispersed it would seem crucial to consider what role, if any, these geographical arrangements have on sexual offending.

The primary purpose of this paper is, therefore, to begin to explore what value, if any, a geographical approach to the study of sexual offending might offer. Utilising published official data from England and Wales it presents for the first time geographical analyses of the registration, risk assessment and management of RSOs across 42 MAPPA areas of England and Wales. ${ }^{4}$ In doing so it considers and evaluates the methodological issues pertaining to the use of such data and such a geographical approach. The paper then discusses the implications of this largely descriptive analysis for future research and how this might be beneficial in evaluating the effectiveness of the current system of control for RSOs, including the limitations of such an approach. We should be clear that it is not our intention to use this initial analysis to offer new insights into sexual offending. Instead we hope it will begin a discussion as to what a geographical approach can offer and how it can be used alongside other approaches to the study of sexual offending.

The remainder of this paper is structured in the following four ways. First, we outline the multiagency approach to the management of RSOs that is employed across England and Wales. Second, we describe how the data were collated and prepared for analysis. Third, we present the findings from fairly straightforward geographical analyses of the data, before, fourth, discussing these findings and the implications of them for further research and analysis into the incidence and management of sexual offending.

\section{The multi-agency approach}

The development of MAPPA in England and Wales formally established partnership arrangements between various agencies to oversee the assessment and management of high-risk offenders, notably RSOs. The Criminal Justice and Court Services Act2000, in conjunction with the Criminal Justice Act 2003, imposed a statutory duty on the police, probation and prison services to assess and manage the risk presented by violent and sexual offenders in the community. Originating from Multi-Agency Public Protection Panels in the late 1990s MAPPA now controls the community management, containment and surveillance of all "potentially dangerous" offenders in England and Wales. Offenders eligible for MAPPA consideration include:

- Category One: RSOs (who by definition are required to adhere to the sex offender register);

- Category Two: violent or other sex offenders not subject to notification requirements; and

- Category Three: other dangerous offenders.

The legislation requires that a formal risk assessment of eligible offenders is undertaken using risk assessment tools such as the Offender Assessment System, actuarial measures such as Risk Matrix 2000, Structured Assessment of Risk and Need (SARN) for RSOs in treatment programmes, and in the case of young offenders, Asset - Young Offender Assessment Profile. Such tools assist in determining the appropriate level of risk management, information sharing, monitoring and surveillance that is 
needed for each RSO. While the accuracy and predictive validity of actuarial instruments and the appropriateness of their use in sex offender risk-level categorisation have been contested (see for example, Craig, Browne, \& Beech, 2008), the assumption is that the process recognises that the majority of individuals under MAPPA do not present a risk of serious harm to the public, enabling resources to be targeted to those that do. The risk management plan, while specific to each offender, can include restrictive measures such as tagging, supervised accommodation and unannounced visits, as well as intensive one-to-one work with the RSO. The risk management plan will ultimately depend on the risk level of the individual. As risk is dynamic, offenders can be escalated/de-escalated in terms of level of management when risk increases/decreases (see Home Office, 2004, para. 111-116). But, in short, RSOs are managed under MAPPA at one of three "risk levels":

- Level 1: involves "Ordinary Agency Management", which is used in cases where the offender is assessed as low or medium risk of serious harm to others, and can thus be managed by one agency.

- Level 2: involves "Active Multi-agency Risk Management" (previously referred to as "Local Inter-agency Risk Management"). At Level 2 the offender is assessed as posing a high or very high risk of serious harm and thus requires the active involvement of more than one agency.

- Level 3: again involves "Active Multi-agency Management", but is reserved for the management of the "critical few". These are offenders who are deemed to pose the highest risk of causing serious harm, or whose management is so problematic that multi-agency cooperation and oversight at a senior level is required.

The level of multi-agency representation and involvement is thus key to the level at which a RSO is managed. While a statutory duty is placed on the three services outlined above, if a RSO is managed at Level 2 or 3 a number of other agencies are required to cooperate and contribute to the risk management plan. These could include young offender teams, local health authorities, housing authorities and service departments, education authorities, social security and employment service departments and social services. Evidently, the risk assessment exercise can have far-reaching consequences for the individual being assessed, both in terms of the degree of restrictive, rehabilitative and protective interventions put in place to manage risk, and in the extent to which information is shared between agencies involved in MAPPA. Of course, The Child Sex Offenders Disclosure Scheme now also allows information about RSOs to be shared with the public through controlled disclosure (see Chan, Homes, Murry, \& Treanor, 2010; Kemshall et al., 2010). While MAPPA already allowed for the sharing of information to third parties (i.e. non-MAPPA partners) for those offenders deemed to be at the highest risk of causing serious harm, The Child Sex Offenders Disclosure Scheme applies to all RSOs but provides clearer rules around what information can be shared and to whom a disclosure can be made.

\section{Data and methodology}

One of the requirements of the agencies involved in the coordination of MAPPA is the production of an annual report. These reports provide the general public with information on how MAPPA operates and presents statistical information on the individuals monitored across various risk-level categorisations. The primary data used in the present analysis were derived from the annual reports 
for the 42 designated MAPPA areas in England and Wales. These were accessed via the Ministry of Justice website and from the websites of the relevant police force for each area. Reports were examined over a seven-year period from 2004/2005 to 2010/2011.

This paper uses data for Category One RSOs only. This includes the number of RSOs under MAPPA and the number of RSOs managed at Level 2 and Level 3 of risk. The number of Level 1 RSOs was calculated by simply deducting the number of Level 2 and Level 3 RSOs from the total number of RSOs.

It is important to note that the data represent the number of cases included on 31 March for each corresponding year, like a form of census data. The total number of cases that were managed may have fluctuated between each census date. The same also applies to the risk-level allocation of RSOs.

Crucially the same census date was used consistently across all 42 MAPPA areas. However, slight differences were observed when comparing the data with official national statistics provided by the Ministry of Justice. These minor differences can possibly be explained by timing differences in the recording of data between the Ministry of Justice and individual MAPPA areas, and due to the outcome of some convictions or cautions being overturned at a later date on appeal. For the majority of statistics, however, the number of RSOs over the seven-year period was broadly consistent with the figures provided within Ministry of Justice statistical bulletins.

In order to make meaningful comparisons of the data by MAPPA area it was necessary to take into account differences in the relative population size of each area. This was achieved by standardising the number of RSOs per 10,000 of the population in each MAPPA area. ${ }^{-}$These standardised figures, or rates, ensure that for the first time meaningful geographical comparisons in the incidence of RSOs across England and Wales can be made.

In the analysis that follows we tend to report figures for several years combined and illustrate the results using choropleth maps, dividing MAPPA areas into five ranked groups of equal size. These analytical strategies have been employed for two main reasons. First, they avoid having to report actual numbers of RSOs. Clearly reporting the incidence of RSOs is a sensitive topic and media coverage of the data tends to "sensationalise" the number of RSOs in a given area without any attempt to stress how relatively small the number of offenders are given the size of the population in the area. Second, given the small numbers we are concerned about any comparisons over time, particularly at the level of MAPPA areas, are susceptible to relatively significant annual fluctuations. By combining data over years or by presenting categorical results we hope to minimise any misinterpretations from the analysis but whilst still producing meaningful and useful insights into the data.

\section{Analysis of MAPPA data on RSOs}

\section{General trends in RSOs across England and Wales}

Before presenting geographical analyses of data on RSOs by MAPPA areas it is useful to first examine the data over time at a national level. Figure 1 shows the total number of RSOs across England and Wales between 2004/2005 and 2010/2011. Figure 1 also charts the number of those RSOs by the level of risk that they are being managed at within their MAPPA area. 
Figure 1. Number of RSOs over time for England and Wales based on MAPPA annual reports.

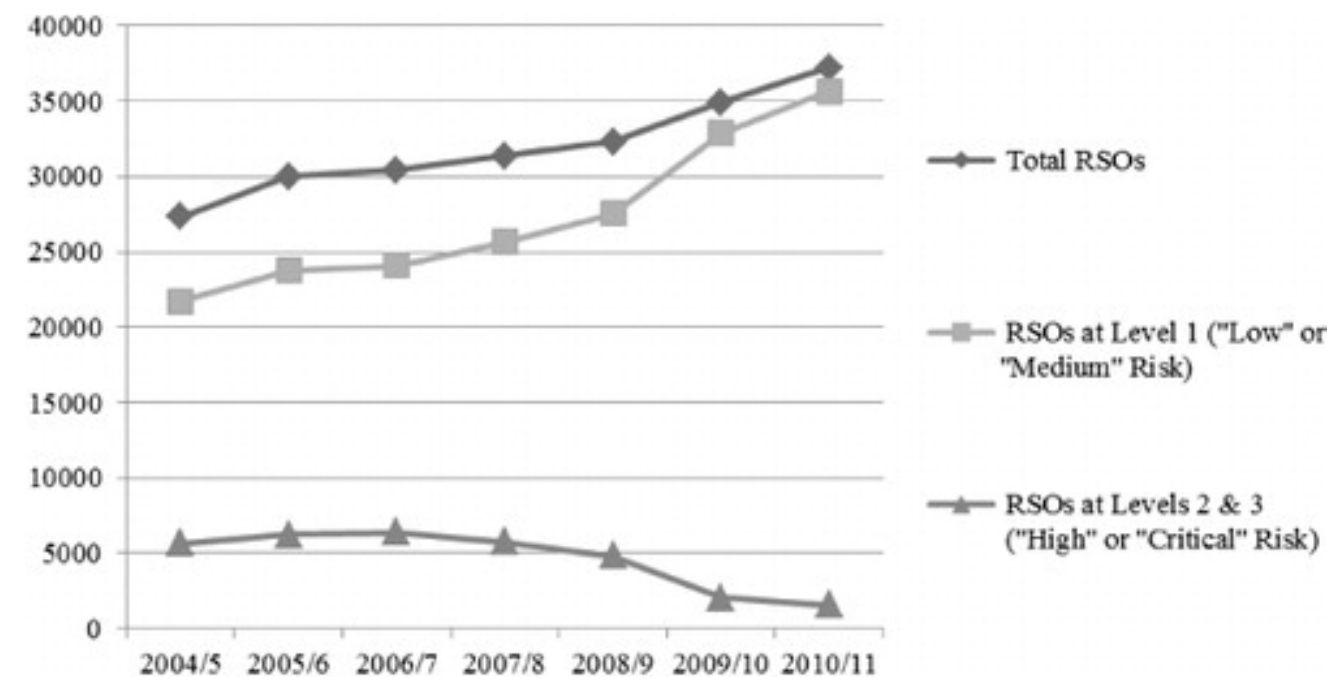

Over the seven-year period the overall number of RSOs in England and Wales has steadily risen between each year for which data were recorded. The sex offender register requires convicted sex offenders to register for a minimum of five years up to an indefinite period. Given the cumulative effect of the notification requirements, this increase is to be expected. Predictably there are fewer individuals leaving the register than are joining it. However, despite the consistent (and expected) increase in the total number of RSOs, the numbers being managed at the "high" and "critical" levels of risk (i.e. Levels 2 and 3) has shown a marked decrease, particularly after 2006/2007. As a proportion of RSOs this is even more startling. This would suggest that MAPPA authorities must have "re-classified" the risk level of a significant number of RSOs over this time period; from Levels 2 to 3 down to "low-/medium-risk Level 1. By 2010/2011 just over 4\% of RSOs were being managed at high or critical risk compared with over $20 \%$ in $2004 / 2005$. Later in the paper, we consider whether this marked decrease can be explained by (1) the reversal or readjustment to the "precautionary" use of the "high- and critical-risk levels at the beginning of the period (Kemshall \& Wood, 2008); (2) fewer high-risk RSOs over this time period; (3) the fact that risk can and will change; and (4) institutional differences.

\section{Geographical comparison of RSOs within the population}

A key aim of this paper is to examine how the number of RSOs in England and Wales is distributed nationally. Figures derived from MAPPA areas were standardised using population estimates to ensure comparability. This provided an estimate of the "density" or "rates" of RSOs within the population for each MAPPA area. Figure 2 illustrates very clearly differences in the average rate of RSOs and in the average rate of those offenders who were managed at high or critical risk between 2004/2005 and 2010/2011. This shows that MAPPA areas with the lowest rates of RSOs overall have less than five per 10,000 of the population. This contrasts with MAPPA areas with the highest rates of RSOs that are found to have more than seven RSOs per 10,000 of the population. Although the numbers are small these differences suggest that there are one and a half times more RSOs per head of the population in some areas of England and Wales than in other areas.

Figure 2. Rates of RSOs within MAPPA areas. 

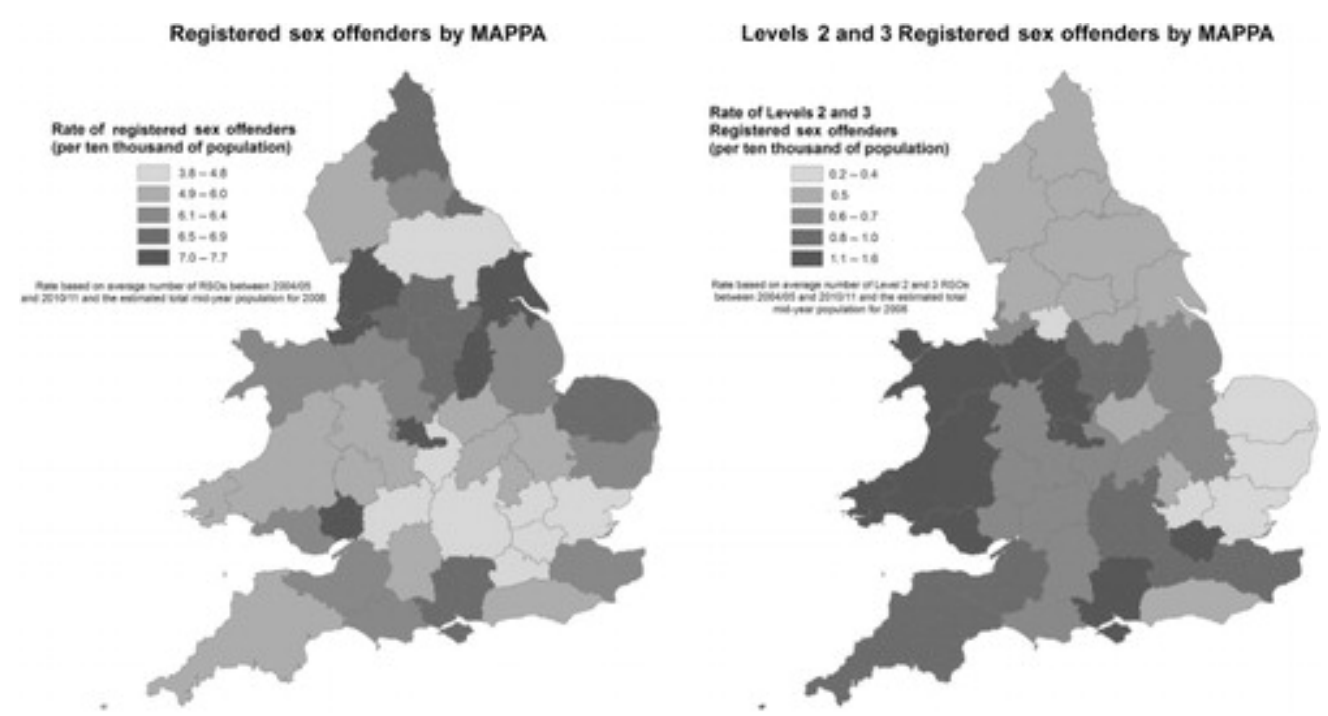

As noted above, the rates of RSOs managed at risk Levels 2 or 3 are very small. However, there are equally sizeable variations in the rates of RSOs managed as "high" or "critical" risk (MAPPA Levels 2 and 3) between MAPPA areas. Here, MAPPA areas vary in the rate of Level 2 or 3 RSOs 0.2 per 10,000 of the population to 1.6 per 10,000 of the population, which is up to four times as many Level 2 or 3 RSOs per head of population. The two maps presented in Figure 2 also demonstrate that having a relatively high population or rate of RSOs in a given MAPPA area is not necessarily indicative of a relatively high rate of RSOs assessed by the MAPPA authorities as being of "high" or "critical" risk to the public.

Figure 2 would suggest that there is a geography of sexual offenders, or at least "RSOs", across England and Wales that requires further consideration. The analysis of Level 2 or 3 (high or critical risk) RSOs would also suggest that either there is a different geography of RSOs depending on the level or risk they pose to the public and/or there are significant differences in the way in which MAPPA areas assess the risk that RSOs pose.

Despite the cumulative growth in the number of RSOs over time (see Figure 1) the relative rates of RSOs by MAPPA area appears to be surprisingly stable over time. Figure $3 a$ and b compares the "rolling average" rates of RSOs between two time periods: 2004/2005-2006/2007 and 2008/20092010/2011. From this analysis it is possible to identify MAPPA areas that had a consistently high rate of RSOs over time, such as the West Midlands, Lancashire, Nottinghamshire and Humberside, and MAPPA areas that had a consistently low rate of RSOs over time, such as Essex, London, Thames Valley, Surrey, Hertfordshire, Gloucestershire and North Yorkshire. Figure 3b shows that relative differences in the rates of RSOs between MAPPA areas appear to be remarkably stable over time. ${ }^{-}$To some extent this might reflect the cumulative effect produced by long notification periods for RSOs, but perhaps might also reflect a persistent geography of RSOs over time. 
Figure 3. (a) Change in rates of RSOs over time by MAPPA area and (b) Comparison of the rate of RSOs over time.

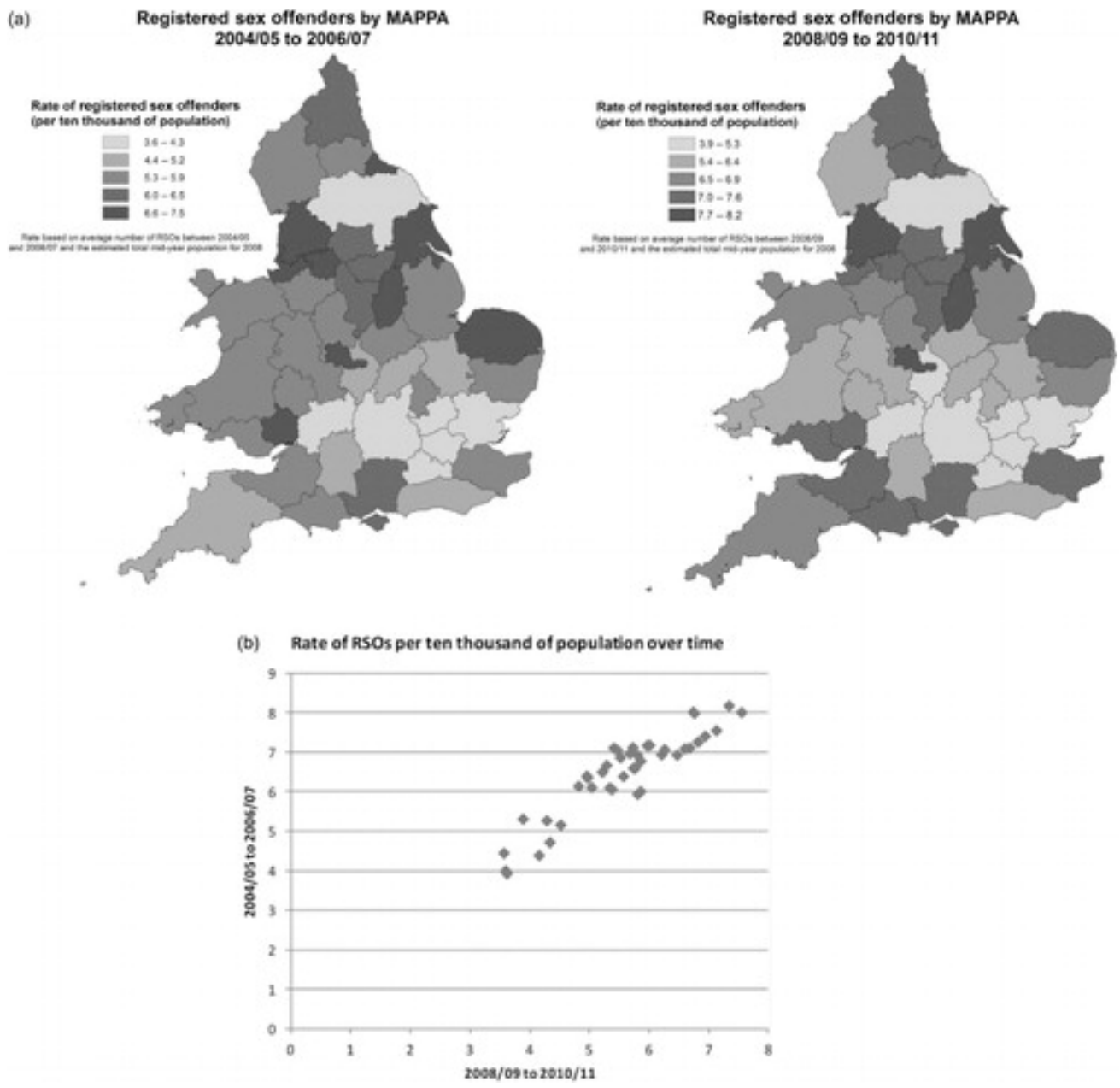

Despite the relative stability in the rates of RSOs over time further analysis of the incidence of RSOs by their managed level of risk reveals a very different picture, adding further to the suggestion that there are significant differences in the way in which MAPPA areas are assessing risk (and reclassifying risk). As we already showed in Figure 1 there has been a dramatic reduction in the number and proportion of RSOs managed at high- and critical-risk Levels 2 or 3 over time. However, Figure 4 illustrates that this decline in the frequency or reclassification of high-risk sexual offenders has not been consistent across all MAPPA areas. Crucially, Figure 4 compares the distribution of Level 2 or 3 risk allocations across the MAPPA areas for the period 2004/2005 to $2006 / 2007$ with the period $2008 / 2009$ to $2010 / 2011$. This new comparison shows that a number of MAPPA areas have actually had a consistent proportion of high-risk RSOs over time, either with consistently high rates, such as in London and across Wales, or with consistently low rates, such as Greater Manchester. But even where MAPPA areas have seen a significant decline in the proportion of high-risk RSOs the rate of decline has not been consistent across MAPPA areas. ${ }^{.}$ 

area.
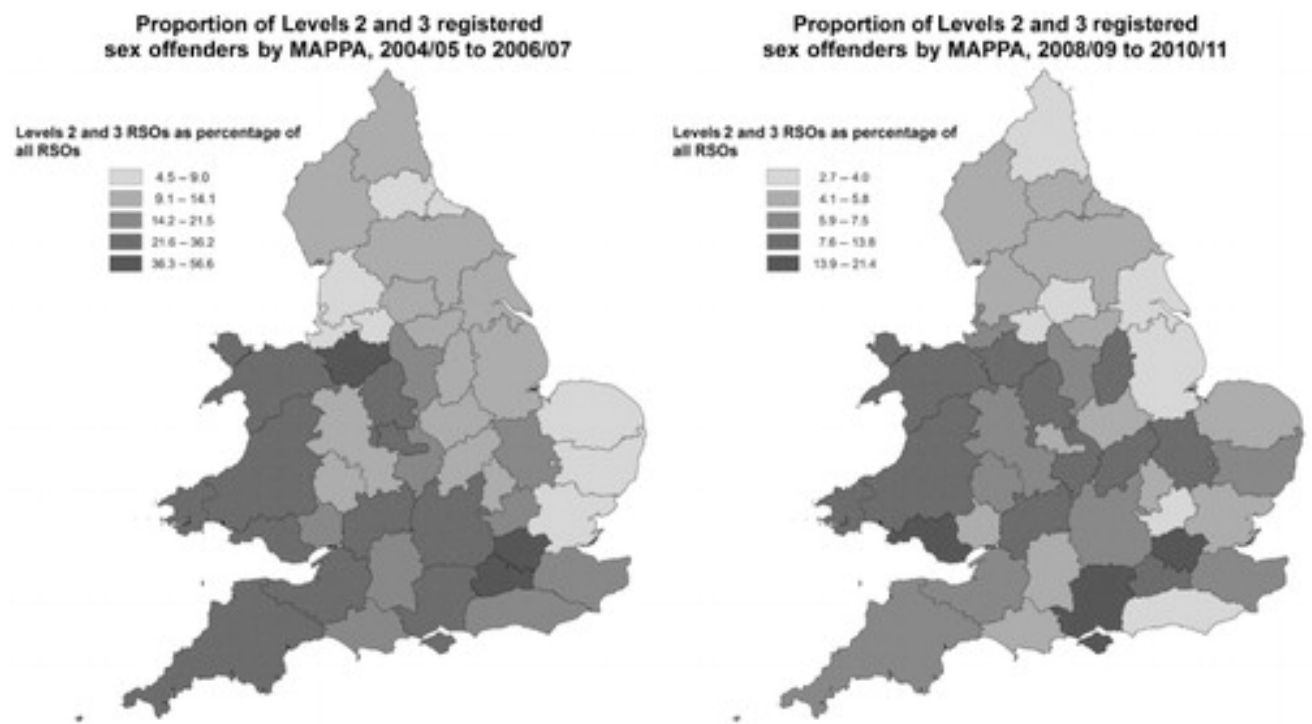

\section{Discussion}

In the introduction to this paper, we gave two reasons why a geographical analysis of "expressive" crimes such as sexual offending might be useful: (1) that there might be a geography of sexual offenders and sexual crime that could offer new insights into understanding this offending behaviour and (2) that there might be a geography of the control systems designed to manage the crimes which may in effect have a role in determining levels of criminal activity. Indeed, this relatively simple analysis of official data relating RSOs across the 42 MAPPA areas of England and Wales begins to suggest that both may be valid and are worthy of further exploration. Understanding the geographical differences that have been highlighted above is beyond the scope of this paper and would be difficult to achieve without further analysis and research. However, this initial geographical analysis of existing data does offer new insights and helps to raise new questions about the way in which we study sexual offending and how sexual offending is managed.

\section{A geography of sexual offending}

Clearly this analysis and the data we have used cannot provide a complete account or presentation of a geography of sexual offending across England and Wales. Critically it relies entirely on the recording and current location of RSOs. For example, first, it did not include the incidence of sexual crimes that go unreported or for which no convictions have been made. Second, it does not take into account the number of sexual crimes that each RSO might have committed. And third, there is no assurance that just because a RSO is currently resident in one MAPPA area that they committed any sexual offence in that area. It is also possible that due to the relatively large geographical coverage of MAPPA areas and the relatively small numbers of RSOs in each area that any apparent differences are susceptible to statistical chance or unsystematic error. (Although it should be noted that statistical tests are not necessary when analysing population data such as this.) But the validity of findings presented here depends on whether these limitations or caveats are likely to have occurred to the same extent across all MAPPA areas. If they have, then any patterns we have identified in this 
analysis are very likely to still exist. If, however, there were systematic geographical differences in the presence of these limitations then they could account for the geographical variations we have identified. An example of this could be systematic geographical differences in where prisons for sexual offenders are located and hence where they are resettled following release from prison. But while there may be systematic differences that could account for some of the geographical variations between MAPPA areas found above it is still unlikely that all the variation can be accounted for by the limitations of this analysis. For example, it is quite likely that the incidence of under-reporting of sexual crimes, although disappointingly too high, is likely to occur at similar rates in each MAPPA area.

Therefore the geographical patterns we have identified above are likely to be the result of a combination of differences in the rates of convictions across the different MAPPA areas, the risk assessment process, factors around their resettlement and specifically the rehousing of convicted sex offenders and a "geography of sexual offending". This analysis, then, certainly invites us to at least question the degree to which the localities of RSOs may influence their offending behaviour.

Further discussion of the geographical findings presented here or more detailed analysis using additional data may provide further insights into this. However, it would seem more likely that only by utilising a geographically oriented approach to understanding sexual offending alongside other psychological and sociological approaches to understanding sexual offending behaviour will it be possible to understand the relatively importance of such a complex array of factors that are likely to constitute "expressive" criminal behaviour.

\section{A geography of control systems}

If a "geography of sexual offending" only remains a tentative suggestion following this analysis the same cannot be said for a "geography of control systems" and the implications that this might have on sexual offending. While it is not possible with this form of analysis to disentangle all the possible explanations for between-area differences in the presence of sexual offenders, the uneven distribution of RSOs that we have seen clearly raises a number of issues for policy and practice.

The first issue relates to resourcing of MAPPA areas and their partner agencies. While again we need to stress the overall numbers are small, the significant differences in the presence of RSOs across England and Wales that we have identified pose important resource implications for MAPPA areas and the NOMS. Should resourcing of MAPPA follow the number of RSOs or can the uneven distribution of RSOs and the resulting uneven demands on the respective authorities be reduced, possibly through processes of resettlement?

This leads to a second set of policy issues relating to sentencing and resettlement. As we have already discussed the existence of variations in the rates of RSOs within the different MAPPA areas may reflect where they are being sentenced or rehomed. It has, for example, long been recognised that different "court cultures" effect the working practices of the Crown Prosecution Service and other practices and professionals working within this constitutional setting. The geographical analysis presented here might therefore reveal a lot about fairness and legitimacy across the criminal justice system. It is from this detailed analysis that we are then able to afford greater consideration and scope to address the principles underlying different court cultures and ideologies. 
Similarly, a geographical understanding of where RSOs are resettled or rehoused allows us to fully recognise the differential impacts of these policies. For instance, we know local communities often have significant concerns surrounding the presence of sexual offenders in their communities, and that this often influences the housing options available for RSOs. So much so that the residential locations of RSOs have become a crucial part of multi-agency partnerships, with social housing providers seen to be an essential and necessary component to their effective management (Cowan, Pantazis, Gilroy, \& Bevan, 1999; Cowen, Pantazis, \& Gilroy, 2001). If relatively large numbers of RSOs (although of course we are still referring to relatively small numbers given the size of the population area) are clustered within social housing, this has implications for risk escalation. Relatively high numbers of RSOs are likely to live in less desirable residential areas, characterised by greater social disorganisation and marginalisation (Cowen et al., 2001; Mustaine, Tewksbury, \& Stengel, 2006). Could the geography of sexual offenders that results from such resettlement practice go on to influence rates of reoffending? Current research suggests that feelings of isolation, disempowerment, depression and lack of social support may inadvertently increase a sexual offender's risk of reoffending (Wilson \& Yates, 2009). In the USA, geographical analysis using GIS has been used to try and "improve" the resettlement of sexual offenders in order to minimise some of these potential issues (Mulford, Wilson, \& Parmley, 2009; Murray \& Grubesic, 2012).

If it is accepted that the rehousing of RSOs has become a core component of multi-agency working, the variations in the incidence of RSOs within the general population may also be influenced by existing post-release controls, including the extended supervisory oversight and monitoring of sexual offenders through the sex offenders register, associated court orders and the public disclosure scheme. It is therefore not implausible to argue that any significant increase in the use of "limited" or "controlled" public disclosure (see Chan et al., 2010; Kemshall et al., 2010) may affect future geographical trends. Indeed, research conducted by Kemshall, Dominey, and Hilder (2012) exploring the perception of the scheme by RSOs found that RSOs that had experienced some form of disclosure (either self-disclosure or through media attention) had faced "difficulties in obtaining ... appropriate housing" (p. 319). While this was not realised in the pilot scheme (Kemshall et al., 2010) there is a danger that the increasing use of the disclosure scheme may exacerbate the shortage of housing options for sex offenders and further "displace" RSOs across MAPPA areas.

Another issue of control relates to the assessment of risk. Our data highlight both significant geographical variations in the rates of Level 2 or 3 RSOs between MAPPA areas and significant differences in these levels of risk over time. To reiterate while the overall number of RSOs has increased over the seven-year time frame, those assessed to be the greatest risk appear to have declined quite significantly, but this decline has not occurred at the same rate in every MAPPA area.

The fact that the proportion of RSOs managed as high or "critical" risk remained relatively consistent over the first two years in our analysis paper (2004/2005-2005/2006) is consistent with Feeley and Simon's (1992)" new penology" and notions of "penal populism". Both have shifted the focus towards containing the risk posed (or perceived to be posed) by sexual and dangerous offenders within the "community protection model" which MAPPA epitomises (Connelly \& Williamson, 2000). These "new" objectives would easily explain the apparent inflation of offenders assessed as high or "critical" risk at the beginning of the period. Indeed, Kemshall and Wood (2008) have described the assessment of the "critical few" during this period as "elastic in practice", whereby a "precautionary", "better safe than sorry" approach was taken (p. 618). 
However, policy changes to the definition of the "critical few" were made in the 2003 MAPPA guidance (Home Office, 2003). This might help to explain the downward trend of RSOs assessed to be the greatest risk. But Kemshall and Wood (2008) have argued that attempts to refine the definition of the "critical few" actually extended the criteria qualifying RSOs to this high level of risk management.

A positive interpretation of the findings from this analysis could therefore be that the significant decline in the numbers being managed at high and critical risk signifies a break from "precautionary principles and defensive responses" to the perceived risks of sexual offenders (Kemshall \& Wood, 2008, p. 611). However, there are a number of other ways that these findings could be interpreted.

One alternative explanation may be that there are genuinely fewer high-risk RSOs over this time period. Similarly, the downward trend in the number of high-risk sex offenders could be an indication that MAPPA was working well. Given that the risk assessment process is described as a "continuous process", which involves "close monitoring and reassessment of dynamic factors" (Wood et al., 2007, p. 12), the effective management of high-risk RSOs may result in a decline in the number of high-risk offenders. However, if one or both of these explanations were valid would the decline in numbers be as dramatic as the analysis suggests? Even if this were the case why would the rate of decline vary so dramatically between MAPPA areas?

The most likely interpretation of these findings is that they reflect significant shifts in practice of risk assessment within each MAPPA area. The overall decline may reflect a national (England and Wales) response or pressure to reduce the use of high-level risk allocations. But some MAPPA areas were either using these high-level risk allocations sparingly throughout the period (i.e. those with consistently low levels of Level 2 or 3 ) or appear to be rejecting any pressure or need to reduce the use of these high-level risk allocations.

Either way, the variations shown by this analysis most likely reflect institutional differences in the way that risk is being assessed across the 42 designated MAPPA areas in England and Wales. Risk assessments rely on subjective decision-making and as a result have been criticised for being notoriously open to bias (Kemshall, 2008). Differing risk perceptions will invariably impact on how different professionals define and assess risk. Risk assessment tools have been introduced to negate such bias and to assist the determination of the appropriate level of risk management (Miller \& Maloney, 2013). However, as this paper has already noted, different tools are used on different offenders (SARN for example is used for RSOs in treatment programmes), and by different practitioners (this responsibility falls to the agency that has the leading statutory responsibility for each offender, i.e. the "Responsible Authority"). Furthermore, the accuracy and predictability value of these tools have been rigorously contested. All these factors could impact on geographical and organisational differences in risk levels. While MAPPA guidance aims to negate any bias, the variation in the rates of Level 2 and 3 RSOs between MAPPA areas also questions whether the guidance is clear enough to ensure that all MAPPA areas follow it in the same way.

Clearly this analysis has a number of limitations. First, it cannot say anything about why there may be geographical variations in the assessment of risk across MAPPA areas. Only further detailed research, such as that undertaken in the USA (for example, Tewksbury \& Mustaine, 2013), into the practices and attitudes of MAPPA staff would reveal this. And second, the analysis in this paper is 
unable to show what kind of impact these varying practices of control have on sexual offending, and in particular, reoffending. For example, in the USA, Socia (2013) used a similar geographical approach to find that the clustering of RSOs was positively associated with modest increases of recidivistic sex crime arrest rates. Further statistical analysis using data from over a longer period of time which utilises reoffending data might be useful in the UK too. But equally research with offenders themselves may also be very revealing in terms of what impact differences in the control systems (i.e. MAPPA areas) across England and Wales may have on their attitudes towards their offences and future offending behaviour.

Fundamentally, the level of variations in practice shown in this paper undermines a system that is based upon risk levels. In doing so, it inevitably raises a number of human rights concerns. As this paper has already discussed the level of risk at which a RSO is managed has implications in terms of their rights and autonomy. It is therefore imperative that the process is fair and consistent across England and Wales, which unfortunately these findings suggest may not be the case. Similar concerns have also been raised with regard to how RSOs in England and Wales will be managed within the UK Government's Transforming Rehabilitation (TR) strategy, which is set to reconfigure the way traditional probation services are commissioned and delivered in the future by risk of harm (Ministry of Justice, 2013a, 2013b). The strategy sets out a division between the management of high-risk offenders by the National Probation Service, and the marketisation of services to manage low- to medium-risk offenders by Community Rehabilitation Companies (CRC), ${ }^{9}$ adding competition to the already complicated nature of risk assessment. In a special edition of the British Journal of Community Justice (which provides a considered overview of the TR strategy), Calder and Goodman (2013) raise concerns that the risk assessment process could become linked with fiscal gain, "leading to service user's risk being assessed as higher or lower dependent on the desired outcome to keep them with or send them to the national service or CRC" (p. 182). Fitzgibbon (2013, p. 90) correctly reminds us of how private companies have "already (allegedly) demonstrated an ability to technically defraud the government" drawing on the Serco/G4S fiasco (Travis $\underline{2013}$ ). It is not therefore unreasonable to assume that problems associated with defining and assessing risk will be amplified if contract renewal is the reward (Fitzgibbon, 2013).

\section{Conclusion}

In this paper, we set out to consider whether a geographical approach to studying "expressive" crime, such as sexual offending, could offer useful insights or prompt further research. Two main reasons for this were given: (1) to see whether a geography of sexual offending exists and what implications this might have on understanding sexual offending and (2) to consider what role a geography of control systems, in this case the criminal justice system for RSOs, for which MAPPA is a key component, might have on the way in which such offenders are managed or controlled.

Collating and utilising data published by the 42 MAPPA areas of England and Wales we were able to examine the spatial patterns of two sets of data, each designed to reflect the two geographies highlighted above: (1) the incidence of RSOs and (2) the levels of risk at which these offenders are managed or controlled. Although both can only be considered to be proxies for the underlying geographies of sexual offending and control systems they nevertheless provided important insights which would certainly suggest that further geographical analyses in this area would be both useful and important to pursue. However, throughout the analysis we also highlighted the limitations of 
using this kind of data and approach to offer any new understanding of sexual offending. The analysis that supports a geography of sexual offending was significantly constrained by the partial nature of the data, whilst analysis in support of a geography of control systems was significantly constrained by its inability to provide causal explanations or to demonstrate what the impact of this might be on future sexual offending. However, the tentative findings presented here would suggest that further exploration and study of these issues are warranted, both for understanding sexual offending and for evaluating the policies and practices that are in place to manage sexual offenders.

Crucially, we would argue, the geographical interpretations outlined here of both the incidence of RSOs and the rates of risk allocations between MAPPA areas provide valuable insights that both inform and question the current TR strategy in England and Wales. First, it provides some clarification on how the new provider landscape will look and function following the marketisation of probation services. In doing so, it can help ensure that resources are appropriately targeted across the 42 MAPPA areas. Indeed, the cost of resourcing MAPPA practices over time could account for the apparent downwards trend in the use of high-risk categories in the risk-level allocation since $2006 / 2007$. The cumulative nature of sex offender registration (for all risk levels) means that resourcing the management of RSOs will also be increasing over time, adding a further burden on the management of those deemed to be the highest risk. It is therefore imperative that we have accurate data on the rates and whereabouts of RSOs in the current period of austerity and change. And second, it reminds us that the practices of managing (and controlling) RSOs is a social process and are susceptible to variations in those practices that may not necessarily reflect their intended design and guidance. In an era of increased marketisation in the control of offenders, particularly in terms of the resettlement and support for RSOs, procedures need to be put in place that can monitor and identify mistaken or possibly dishonest practices.

\section{Notes}

1. Similar arrangements exist in Scotland and Northern Ireland. However, they each have, in the main, their own legal, judicial and criminal justice systems.

2. MAPPA areas are aligned to existing police force areas across England and Wales. But these regional areas are very distinct from other administrative geographies that currently exist in England and Wales. For example, there are currently 42 MAPPA and police force areas in England and Wales compared with 11 strategic health authorities (until 2013) and 368 local authorities.

3. While we are not uncritical of the use of the term "offender" in relation to individuals who are not necessarily still involved in criminal offending, we use the term Registered Sexual Offender, or RSO for short, within this paper, merely due to its use as a category within the official MAPPA documentation.

4. As noted before, the criminal justice systems of Scotland and Northern Ireland are very distinct to that of England and Wales and, in the main, have their own legal systems. Therefore, the analysis and discussion presented here relate to England and Wales alone, even though all four countries are part of the UK.

5. Additional data from the MAPPA annual reports were also analysed. This included the number of Sexual Offences Prevention Orders and the number of RSOs who breached their notification 
requirements, including the penalty sanctioned. However, space does not allow for the presentation and discussion of these additional analyses, and these will form the basis of future reporting.

6. Population estimates are based on a census taken every 10 years in the UK. The Office for National Statistics (ONS) then calculates annual estimates of the resident population for each year between censuses - these are referred to as mid-year population estimates. These are routinely published for each local authority across England and Wales. Since the MAPPA data used in this analysis fell between Censuses the analysis used the ONS mid-year population estimates. Population estimates for each MAPPA areas were derived by aggregating the 2008 mid-year population estimates from the local authorities that constitute each MAPPA area. The year 2008 was selected to represent the mid-point of the MAPPA data available.

7. This has a correlation of $R^{2}=.84$.

8. This has a correlation of only $R^{2}=.24$.

9. CRC will consist of private, voluntary sector and mutual organisations, commissioned by Payment by Results.

\section{References}

- 1. Bottoms, A. E. (2007). Place, space, crime and disorder. In M. Maguire, R. Morgan, \& R. Reiner (Eds.), The Oxford handbook of criminology (4th ed., pp. 528-574). Oxford: Oxford University Press.

- 2. Burgess, E. W. (1928). The growth of the city. In R. Park, E. W. Burgess, \& R. D. Mckenzie (Eds.), The city (pp. 47-62). Chicago, IL: University of Chicago Press.

- 3. Calder, S., \& Goodman, A. H. (2013). Transforming rehabilitation, a fiscal motivated approach to offender management.British Journal of Community Justice, 11, 175-188.

- 4. Chan, V., Homes, A., Murry, L., \& Treanor, S. (2010). Evaluation of the offender community disclosure pilot. Scotland: IPSOS MORI.

- 5. Cohen, J. (1941). The geography of crime. Annals of the American Academy of Political and Social Science, 217 (1), 29-37. doi:10.1177/000271624121700105 [CrossRef]

- 6. Cohen, L. E., \& Felson, M. (1979). Social change and crime rate trends: A routine activity approach. American Sociological Review, 44, 588-608. doi:10.2307/2094589 [CrossRef], [Web of Science ${ }^{\circledR}$ ], [CSA]

- 7. Connelly, C., \& Williamson, S. (2000). Review of the research literature on serious violent and sexual offenders. Edinburgh: Scottish Executive.

- 8. Cowan, D. S., Pantazis, C., Gilroy, R., \& Bevan, M. (1999). Housing sex offenders: An examination of current practice. Coventry: Joseph Rowntree Foundation and Chartered Institute of Housing. 
- 9. Cowen, D. S., Pantazis, C., \& Gilroy, R. (2001). Social housing as crime control: An examination of the role of housing management in policing sex offenders. Social \& Legal Studies, 10, 435. [Web of Science ${ }^{\circledR}$ ], [CSA]

- 10. Craig, L., Browne, K. D., \& Beech, A. R. (2008). Assessing risk in sex offenders: A practitioner's guide. Chichester: Wiley.[CrossRef]

- 11. Feeley, M., \& Simon, J. (1992). The new penology: Notes on the emerging strategy for corrections. Criminology, 30, 449-475. doi:10.1111/j.17459125.1992.tb01112.x [CrossRef], [Web of Science ${ }^{\circledR}$ ], [CSA]

- 12. Fitzgibbon, W. (2013). Risk and privatisation. British Journal of Community Justice, 11(2/3), 87-90.

- 13. Home Office. (2003). MAPPA guidance (version 1). London: Author.

- 14. Home Office. (2004). MAPPA guidance. Multi-agency Public Protection Arrangements. Protection through partnership (version 1.2). London: Author.

- 15. Hudson, K. (2005). Offending identities: Sex offenders' perspectives of their treatment and management. Devon: Willan.

- 16. Kemshall, H. (2008). Understanding the community management of high risk offenders (1st ed.). Maidenhead: Open University Press.

- 17. Kemshall, H., Dominey, J., \& Hilder, S. (2012). Public disclosure: Sex offenders' perceptions of the pilot scheme in England. Compliance, legitimacy and living a "Good Life". Journal of Sexual Aggression, 18, 311-324. [Taylor \& Francis Online], [Web of Science ${ }^{\oplus]}$

- 18. Kemshall, H., Wood, D.J., Westwood, S., Stout, B., Wilkinson, B., Kelly, G., \& Mackenzie, G. (2010). Child sex offender review (CSOR) public disclosure pilots: A process evaluation, Home Office research report 32. London: Home Office.

- 19. Kemshall, H., \& Wood, J. (2008). Risk and public protection: Responding to involuntary and 'taboo' risk. Social Policy and Administration, 42, 611-629. doi:10.1111/j.14679515.2008.00627.x [CrossRef], [Web of Science ${ }^{\circledR}$ ]

- 20. Lowman, J. (2005). Conceptual issues in the geography of crime: Toward a geography of social control. Annals of the Association of American Geographers, 76(1), 81-94. doi:10.1111/j.1467-8306.1986.tb00105.x [Taylor \& Francis Online], [Web of Science $\left.{ }^{\circledR}\right]$

- 21. Miller, J., \& Maloney, C. (2013). Practitioner compliance with risk/needs assessment tools: A theoretical and empirical assessment. Criminal Justice and Behavior, 40, 716-736. doi:10.1177/0093854812468883 [CrossRef], [Web of Science ${ }^{\circledR}$ ]

- 22. Ministry of Justice. (2013a). Transforming rehabilitation: A strategy for reform. London: Author. 
- 23. Ministry of Justice. (2013b). Transforming rehabilitation: Target operating model, rehabilitation programme. London: Author.

- 24. Mulford, C. F., Wilson, R. E., \& Parmley, A. M. (2009). Geographic aspects of sex offender residency restrictions: Policy and research. Criminal Justice Policy Review, 20(1), 3-12. doi:10.1177/0887403408327683 [CrossRef]

- 25. Murray, A. T., \& Grubesic, T. H. (2012). Spatial optimization and geographic uncertainty: Implications for sex offender management strategies. International Series in Operations Research \& Management Science, 167, 121-142. doi:10.1007/978-1-4614-08062_5 [CrossRef]

- 26. Mustaine, E. E., Tewksbury, R., \& Stengel, K. M. (2006). Social disorganization and residential locations of registered sex offenders: Is this a collateral consequence? Deviant Behavior, 27(3), 329-350. doi:10.1080/01639620600605606 [Taylor \& Francis Online], [Web of Science $\left.{ }^{\circledR}\right]$

- 27. Peck, M. (2011). Patterns of reconviction among offenders eligible for Multi-agency Public Protection Arrangements (MAPPA). Ministry of Justice Research Series 6/1. Retrieved from https://www.gov.uk/government/publications/multi-agency-public-protectionarrangements-mappa-patterns-of-reconviction

- 28. Peet, R. (1975). The geography of crime: A political critique. The Professional Geographer, 27, 277-280. doi:10.1111/j.0033-0124.1975.00277.x [Taylor \& Francis Online], [Web of Science ${ }^{\circledR}$ ]

- 29. Socia, K. M. (2013). Too close for comfort? Registered sex offender spatial clustering and recidivistic sex crime arrest rates.Sex Abuse, 25, 531-556. doi:10.1177/1079063212469061 [CrossRef], [PubMed], [Web of Science ${ }^{\circledR}$ ]

- 30. Tewksbury, R., \& Mustaine, E. E. (2013). Law-enforcement officials' views of sex offender registration and community notification. International Journal of Police Science \& Management, 15(2), 95-113. doi:10.1350/ijps.2013.15.2.305 [CrossRef]

- 31. Travis, A. (2013,November 20). Ministers reject G4S offer to repay $f 24 m$ after it admits tagging fiasco. The Guardian. UK News, p. 10

- 32. Vess, J., Day, A., Powell, M., \& Graffam, J. (2013). International sex offender registration laws: Research and evaluation issues based on a review of current scientific literature. Police Practice and Research: An International Journal, 14, 205-218. doi:10.1080/15614263.2012.680719 [Taylor \& Francis Online]

- 33. Wilson, R. J., \& Yates, P. M. (2009). Effective interventions and the good lives model: Maximizing treatment gains for sexual offenders. Aggression and Violent Behavior, 14(3), 157-161. doi:10.1016/j.avb.2009.01.007 [CrossRef], [Web of Science ${ }^{\circledR}$ ]

- 34. Wood, J., Kemshall, K., Maguire, M., Hudson, K., \& Mackenzie, G. (2007). The operation and experience of Multi-agency Public Protection Arrangements (MAPPA): Research and statistics department, online report 12/07. London: Home Office. 